\title{
Eu (não) sou um robô? Elementos para pensar o sujeito nas redes sociais
}

\section{Am i (not) a robot? elements to think the subject in the social networks}

\section{¿Yo (no) soy un robot? Elementos para pensar el sujeto en las redes sociales}

\author{
Diene Eire de Mello ${ }^{1}$ \\ Marta Furlan de Oliveira ${ }^{1}$
}

DOI: http://dx.doi.org/10.20435/serie-estudos.v0i0.1279

\begin{abstract}
Resumo: Este ensaio objetiva refletir, urdido pelos fundamentos críticos da sociedade, a respeito da constituição do sujeito no contexto das redes sociais. De modo particular, pensar esses impactos no processo de rompimento das fronteiras protetoras do indivíduo nessa terra comum. Nesse sentido, a metodologia é de cunho bibliográfico com estudo sobre autores como Batelle (2006), Colbo (2018), Türcke (2010), Zuin (1999; 2014) e outras leituras. Como discussão teórica, o exercício reflexivo é o de evidenciar o domínio opressivo da semiformação mediada pelas redes sociais, uma vez que, com suas produções destinadas ao público (de menor à maior idade), têm estimulado, sugerido, delineado e determinado formas de existência social e individual que direcionam para a reprodução e adaptação dos sujeitos sociais, bem como de seus devires e realidades. Em relação a essa dinâmica, podemos inferir que a cultura digital potencializa a fusão entre o ser humano e a máquina ao ponto de produzir indivíduos "robôs" que são controlados por meio de impulsos elétricos emitidos por chips conectados aos cérebros. Diante disso, tornase imprescindível analisar o modo como as redes sociais redirecionam os sujeitos e suas relações com outros indivíduos em tempos da chamada cultura digital. Os resultados apontam para a possibilidade, pela autorreflexão, da tomada de consciência desse cenário, e permite-nos novos olhares para além das telas da informação e comunicação, no sentido de pensarmos em novos direcionamentos de "ser e estar" no mundo.
\end{abstract}

Palavras-chave: redes sociais; adaptação; sujeito; cultura digital.

Resume: This essay aims to reflect, based on the critical foundations of society, on the constitution of the subject in the context of social networks. In particular, to think about these impacts in the process of breaking the protective frontiers of the individual in this common. In this sense, the methodology is bibliographical with study in authors such as Batelle (2006), Colbo (2018), Türcke (2010), Zuin (1999; 2014), and other readings. As a theoretical discussion, the reflexive exercise

1 Universidade Estadual de Londrina (UEL), Londrina, Paraná, Brasil. 
is to highlight the oppressive dominance of semi-mediation mediated by social networks, since with its productions aimed at the public (from younger to older) they have stimulated, suggested, delineated, and determined forms of social existence and individual that directs towards the reproduction and adaptation of the social subjects, as well as their devices and realities. On these dynamics, we can infer that digital culture potentiates the fusion between the human being and the machine to the point of producing "robots" individuals that are controlled by means of electrical impulses emitted by chips connected to the brains. Therefore, it is essential to analyze how social networks redirect individuals and their relationships with other individuals in times of called digital culture. The results point to the possibility, by self-reflection, of awareness of this scenario, and it allows us to look beyond the screens of information and communication, in the sense of thinking about new directions of "being and to be" in the world.

Keywords: social networks; adaptation; subject; digital culture.

Resumen: Este ensayo posee el objetivo de reflexionar, basado por los fundamentos críticos de la sociedad, acerca de la constitución del sujeto en el contexto de las redes sociales. De modo particular, pensar sobre esos impactos en el proceso de ruptura de las fronteras protectoras del individuo en ese espacio común. En este sentido, la metodología es de cuño bibliográfico con estudio en autores como Batelle (2006), Colbo (2018), Türcke (2010), Zuin (1999;2014) y otras lecturas. Como discusión teórica, la actividad reflexiva es de evidenciar el dominio opresivo de la información incompleta por mediación de las redes sociales, pues las producciones destinadas al público (con edades distintas, de los más jóvenes a los más ancianos) tienen estimulado, sugerido, trazado y determinado las formas de existencia social e individual que encabeza la reproducción y adaptación de los sujetos sociales, así como sus cambios y sus realidades. Acerca de esa dinámica, podemos deducir que la cultura digital potencializa la fusión entre el ser humano y la máquina al punto de producir individuos "robots" que son manejados por los impulsos eléctricos lanzados por chips conectados a los cerebros. Frente a eso, es imprescindible analizar el modo que las redes sociales establecen redirecciones a los sujetos y sus relaciones con otros individuos en el tiempo de la llamada cultura digital. Los resultados indican la posibilidad, por la autorreflexión, de la toma de consciencia de ese escenario, y nos permite nuevas miradas más allá de las pantallas de información y comunicación, en la perspectiva de pensar en nuevos direccionamientos de "ser y estar" en el mundo.

Palabras clave: redes sociales; adaptación; sujeto; cultura digital.1 Introdução

\section{INTRODUÇÃO}

A ideia de que o mundo quer ser enganado tornou-se mais verdadeira do que, sem dúvida, jamais pretendeu ser. (ADORNO, 1986).

Você é um robô? Embora tal questionamento possa aparentar-se simplista e até ingênuo, a ponto de ser respondido por uma criança, neste texto, constitui-se como provocação para pensarmos a respeito do lugar do sujeito/indivíduo 
em tempos de cultura digital. O surgimento do mercado digital ${ }^{2}$ trouxe em seu bojo a possibilidade de interagir com pessoas, acessar, opinar, partilhar e até criar conteúdo em vários formatos. A partir desse momento, a proposta lançada das redes sociais (seus múltiplos aplicativos e usos) foi se alterando e, de maneira expressiva, constituindo-se parte da cultura dos indivíduos na sociedade atual.

Já as redes sociais são criações recentes. ClassMates, por exemplo, é considerada a primeira rede social. Criada em 1995 por Randy Conrads, tinha como objetivo auxiliar os indivíduos/membros a encontrar amigos e colegas de diversas situações da vida diária (escola, trabalho etc.). Mas, somente a partir dos anos 2000, com a criação do Orkut e do Facebook, é que passaram a ser democratizadas ao cidadão comum como redes de relacionamentos.

Tavares e Gomes (2014) explicitam que a criação do Orkut em 2004 foi um divisor de águas, ao permitir o encontro e relacionamento de pessoas por meio de uma rede de computadores. Apesar do sucesso, o surgimento do Facebook em 2006 potencializou essa rede de relacionamentos, sendo que até hoje é a rede social mais utilizada no mundo, por usuários de todas as idades (desde que se tenha ao menos 13 anos, teoricamente). A partir de então, surgiram o Twitter, Instagran, Blogger e tantas outras menos populares. Entretanto, a grande questão que emerge é: como as redes têm influenciado nossa forma de pensar, agir e nos posicionarmos diante da realidade?

Em se tratando do Google - empresa multinacional americana de serviços on-line e software-, é uma maneira recente utilizada para controlar os acessos dos internautas, a fim de garantir um sistema de segurança que substitua o Captcha (Completely Automated Public Turing test to tell Computers and Humans Apart) ${ }^{3}$. O Google, aparentemente, tem a preocupação de verificar, com "certo rigor", os mecanismos de internet que se utilizam de usuários e senhas, uma vez que o "robô" não seria capaz de realizar algumas tarefas, por não ter a observação privilegiada de um internauta, pois opera no sistema interno, e não no externo. Mas a pergunta que não quer calar: e o humano age como um robô?

2 Dominado por "Gafam", que é a abreviatura das cinco grandes empresas dos EUA, nascidas nos últimos anos do século XX ou início do século XXI, tais como: Google, Apple, Facebook, Amazon e Microsoft. Vale informar que a Microsoft foi fundada em 1975, e a Apple, em 1976.

3 É uma palavra formada pela inicial ou por mais de uma letra de cada um dos segmentos sucessivos de uma locução que requer que o usuário identifique as letras de uma imagem distorcida, às vezes, com a adição de uma sequência obscurecida das letras ou dos dígitos que apareçam na tela. Disponível em: https:// pt.wikipedia.org/wiki/CAPTCHA 
Nesse sentido, este ensaio objetiva refletir, urdido pelos fundamentos críticos da sociedade, a respeito da constituição de ser e estar do sujeito no contexto das redes sociais. De modo particular, pensar em relação a esses impactos no processo de rompimento das fronteiras protetoras do indivíduo nessa "terra comum", uma vez que as redes sociais registram estados mentais de bilhões de pessoas, a partir de seus feitos de navegação, conforme explicitado por meio de signos linguísticos. Ou seja, como complementa Batelle (2006, p. 2): "o Google sabe o que a nossa cultura quer".

A partir desse breve panorama, torna-se possível compreender que, até um determinado momento, não tão distante, da história da humanidade, o conceito de redes sociais teve seu uso de maneira tímida e restrita. Somente a partir do século XX é que se transformou num conceito explicativo e revelador da sociedade moderna e pós-moderna e, mais recentemente, numa forma de viver e se relacionar com o mundo, tendo como pano de fundo a avançada tecnologia da informação e comunicação.

Nesse sentido, o presente texto, de caráter bibliográfico, a partir de autores como Batelle (2006), Colbo (2018), Türcke (2010), Zuin (1999; 2014) Castells (2003; 2013) e outras leituras, pretende refletir em relação às questões propostas, no sentido de evidenciar o domínio opressivo da semiformação mediada pelas redes sociais. Isso se deve ao fato de que essas ferramentas, com suas produções destinadas ao público (de menor à maior idade), têm estimulado, sugerido, delineado e até mesmo determinado formas de existência social e individual. Consequentemente, isso tem direcionado os usuários para a reprodução e adaptação enquanto sujeitos sociais, bem como de seus devires e realidades.

Diante disso, torna-se imprescindível analisar o modo como as redes sociais redirecionam os sujeitos sociais e suas relações com outros indivíduos em tempos da chamada cultura digital. Para isso, no primeiro momento, discutiremos "A dinâmica das redes sociais", que, imbricada pela cultura digital, envolve quantidade intensa de informações, produzidas e disseminadas cotidianamente pelas redes sociais. Em relação a essa dinâmica, podemos inferir que potencializa a fusão entre o ser humano e a máquina ao ponto de produzir indivíduos biônicos (robôs?) que são "controlados por meio de impulsos elétricos emitidos por chips conectados aos cérebros" (ZUIN, 2014, p. 242). 
No segundo momento, propomos refletir o "Ser e estar: o rompimento das fronteiras protetoras do indivíduo", que, de modo particular, coloca a condição do indivíduo regida pela cultura digital, promovendo um novo paradigma comunicacional, em que todas as relações sociais tendem a ser concretizadas por meio de telas e displays. Nesse sentido, ser e estar no contexto da cultura digital é ser e estar "tecnologizado" pelas redes sociais que, de maneira sedutora, rompem as fronteiras protetoras do indivíduo e invadem sua vida, seus sonhos, suas formas de pensar, de agir, ou seja, de "ser e estar".

Diante disso, o exercício teórico é compreender parte do funcionamento dessa dinâmica da vida social para, a partir daí, trilhar o caminho da autorreflexão enquanto tomada de posição e resistência ao que está posto neste contexto atual.

\section{A DINÂMICA DAS REDES SOCIAIS: O EMARANHADO DE SENTIDOS}

A forma de organização da rede social (computadores, internet) por meio de algoritmos que fornecem pistas acerca do seu perfil, deixando rastros a partir dos likes, compartilhamento, tempo de leitura, frequência de buscas em termos, é uma arma preciosa na atual sociedade. Assim, ao acessar uma fake news, dar um like e/ou fazer um compartilhamento, estamos automaticamente gerando pistas para que a rede nos ofereça conteúdos similares. Um dos aspectos da cultura digital é a quantidade de informações que nos sãos fornecidas a partir de nossos rastros, não nos permitindo novos olhares, vertentes diferentes, formas de ver a realidade, principalmente ao nos confinar em espaços nos quais as ideias que circulam são similares àquelas que consumimos ou produzimos. Nesse sentido, segundo Lemos (2018), a cultura digital, produtora de controle e monitoramento informacional, multiplica os instrumentos de inscrição eletrônica quando usamos um celular, um cartão de crédito, redes sociais etc.

Como já mencionamos anteriormente, o conceito de rede social surgiu na primeira metade do século XX. Segundo Portugal (2007, p. 4), naquele contexto, "[...] o termo era sobretudo usado em sentido metafórico: os autores não identificavam características morfológicas, úteis para a descrição de situações específicas, nem estabeleciam relações entre as redes e o comportamento dos indivíduos que as constituem".

Desde seu surgimento até os dias atuais, podemos afirmar que a maior contribuição das redes sociais para a sociedade, em sua totalidade, está na articulação 
dos níveis macro e microestruturais que, de certa forma, busca explicar o comportamento dos indivíduos nas redes sociais em que esses estão inseridos. Ainda, além disso, esclarecer a estruturação de tais redes à luz da análise das interações entre os indivíduos e suas motivações humanas. Em consideração aos níveis macro e micro, também na primeira metade do século XX, foi possível a utilização do conceito de "rede social" nas ciências sociais e humanas em função do processo crescente de relação entre o conceito e as práticas sociais de maneira ampla e particular (macro e micro).

O número de seguidores passou a ser matematicamente computado. Os likes e compartilhamentos são monitorados. Os blogueiros, por sua vez, ganham "mais" ou "menos" status e patrocinadores a partir desses quesitos. Ou seja, há uma vigilância e controle de quem emite e quem consome a informação, basicamente um Black Mirror do episódio "Queda Livre". A sociedade do controle de Deleuze (1992) se expressa de maneira clara, sem que ao menos o indivíduo comum tenha a dimensão desses imbricamentos e perceba-se como máquina, como robô, principalmente no que se refere à falsa ideia de liberdade de navegação, pensamento e consumo de produtos.

Hoje, qualquer pessoa que utilize um meio de comunicação está exposta a receber notícias falsas, com fins de propaganda ou manipulação (fake news, mentiras etc.). Sempre houve notícias falsas, mas atualmente a diferença está em que as ferramentas tecnológicas permitem adaptar a história a indivíduos específicos [...]. As assimetrias de poder que hoje vemos na sociedade atual não estão determinadas por estar exposto ou não a essas problemáticas, mas pelo fato de contar ou não com as capacidades ou ferramentas para identificá-las, discriminá-las ou reagir diante delas. (COLBO, 2019, p. 37-8).

As assimetrias apontadas por Colbo expressam um problema crucial da sociedade vigiada: não nos permitir possibilidades de não monitoramento. Afinal, a capacidade das tecnologias de gerar dados relacionados aos nossos anseios, nossas angústias, nossas preocupações, nossa forma de lazer e consumo ocorre em tempo real, cruzando dados a partir de várias fontes e formatos. Dessa forma, a capacidade gigantesca de integração e processamento de diferentes fontes de informação gera formas poderosas de monitorar e influenciar (se é que nós não modificamos) nossos comportamentos (COLBO, 2019, p. 44).

Correndo o risco de sermos pessimistas, há uma programação algorítmica de nossas vidas, produzindo novas formas de sociabilidade e subjetividades. 
Como consequência, a realidade instaurada nos faz refletir acerca do que somos, pensamos e consumimos por meio das redes. Nesse sentido, Lemos (2018, p. 89) aponta que:

Provavelmente os desafios dos próximos anos vão bem além da dinâmica de pontuação das redes sociais e devem migrar para sistemas mais amplos que vão atingir outras áreas da vida pessoal e coletiva. Para além dos pontos em redes sociais, os problemas do futuro estão se aproximando de formas para garantir liberdades de ação, a desprogramação algorítmica, o slow computing, a garantia de proteção da privacidade e do anonimato em meio a performances dos objetos e dos dados, não necessariamente ligados a uma lógica de pontos.

Além dessas novas formas de sociabilidade e subjetividades, as imagens têm se propagado de maneira efetiva no construto atual, pela conotação metafísica universal de que elas bastam em si e por si. Zuin (2014, p. 247), ao referir-se às imagens, afirma que:

[...] seu caráter imediato Ihes provê a condição de verdade irredutível, de modo especial, quando determinadas imagens conseguem vencer a luta titânica que travam com outras, a ponto de sua exposição global capturar a atenção do maior número possível de consumidores de estímulos audiovisuais.

Diante disso, o poderio das redes sociais sentencia a vida do sujeito, seja de forma positiva, seja de forma negativa, sendo utilizado majoritariamente para julgar, controlar e punir por meio de sutis formas de vigilância e de repressão no construto do ambiente digital labiríntico.

\section{SER E ESTAR: O ROMPIMENTO DAS FRONTEIRAS PROTETORAS DO INDIVÍDUO}

Na sociedade regida pela inundação das redes sociais, o que é percebido restringe-se ao que se sobressai, em que o extraordinário e o comum mesclam-se numa confusão engendrada pela sociedade tecnificada e de produção de mercadoria, provocando, de certa forma, a compulsão pelo espetáculo. Türcke (2010) corrobora ao afirmar que "o brilho do incomum faz parte da apresentação de mercadorias totalmente comuns". O autor acrescenta:

Onde o mercado dita o sentido geral da vida, os produtos e os produtores são então enfeitiçados, pois, tais como mercadorias, eles têm seus valores 
aumentados ou diminuídos, são aceitos ou rejeitados. E é dessa forma que ascendem em suas respectivas posições no ranking. Esta é a sua índole: apresentar em tudo a estampa do extraordinário. (Türcke, 2004, p. 62).

A chamada democratização da informação fornece-nos a impressão de que a nossa subjetividade conquista propriedades capazes de compreender e intervir na sociedade. Isso ocorre de tal maneira que as incoerências entre o particular e o global são apenas detalhes técnicos que podem ser resolvidos sem mudança alguma das estruturas sociais.

Todavia, essa ultimação frágil não atinge a manutenção e o fortalecimento de certa desconfiança que paira: aparência de felicidade. Desse modo, Zuin (1999, p. 1) afirma com propriedade que a "fetichização da técnica e a reificação das consciências teimam em nos lembrar que as reconciliações entre o indivíduo e a sociedade, entre o belo e o necessário, o mimético e o construído, o desejo e a cultura não foram ainda concretizadas". Isso posto, seria o que Adorno afirma sobre a reconciliação forçada.

Nesse prisma, ser e estar no contexto das redes sociais é sobretudo ser e estar na universalização da semiformação (Halbbildung) e, por que não dizer, da nossa educação e formação danificada. Isso se deve, principalmente, pela "escoIha" obediente de um modo de vida atrelado aos interesses e às determinações da sociedade do espetáculo e da ilusão que, de certa forma, é constituída para acalentar, pela mercadoria, nossas frustrações e inseguranças em um tempo tão sombrio. Nesse sentido, o fetiche do progresso e da racionalidade instrumental é basicamente o feitiço e a magia consolidados na ilusão de que nunca fomos tão livres como hoje, o que de fato se traduz no inverso. Assim, é possível perceber traços de escravidão de pensamento e a domesticação é sentida e percebida nas publicações em redes sociais, quando o indivíduo se reduz ao estado de "bagatela" aos olhares dos outros.

A esse respeito, enveredamos nossos olhares para o fato de que, em vez de caminharmos em busca de um estado verdadeiramente humano, cada vez mais, as pessoas estão se afundando numa nova espécie de barbárie. E isso nos faz pensar: reunir tantas potencialidades tecnológicas e de informação para chegar a isto? Parece, no mínimo, contraditório.

Enquanto as pessoas, individualmente, divertem-se ou realizam-se nas interações reticulares, trocam mensagens e fotos, 'curtem' um filme, uma 
música, uma notícia ou qualquer ordinário feito de amigos e amigas, como se substituindo ou, talvez, substituindo mesmo, o divertido e despreocupado 'papo de botequim' por um novo formato de 'papo' (ou chat) via computador ou smartphone, grandes corporações empresariais desenvolvem e difundem as tecnologias, serviços e produtos que permitem esses 'papos', nisso auferindo elevadas receitas, altíssimos lucros e ainda maiores ganhos nas bolsas de valores. Seus nomes são bem conhecidos: Apple, Google, Facebook, Microsoft, Samsung, entre outros. (DANTAS, 2014, p. 80).

A rede informatizada, em sintonia com os novos aparatos tecnológicos, apresenta-se como uma modalidade de potencialização de conhecimentos que ampliam perspectivas em termos de pesquisa e interações, porém exige um envolvimento de todos os atores a serem beneficiados, desde as crianças de pouca idade ao adulto de maior experiência. Há, de certa forma, uma dinamicidade com que ocorrem os avanços tecnológicos, tendo em vista o acesso precoce das novas gerações a essa tecnologia marcada pelos computadores, celulares, tablets, notebook etc.

A capacidade de ser e estar no mundo é envolvida pelo definhamento do elemento crítico do pensar diante da cultura digital, em que o indivíduo passa a atuar como mero instrumento a serviço do imperativo das redes sociais. $\mathrm{O}$ pensamento e o conhecimento se veem privados "não só do uso afirmativo da linguagem conceitual científica e cotidiana, mas igualmente da linguagem da oposição" (HORKHEIMER; ADORNO, 1985, p. 12).

É ainda muito otimista pensar que o indivíduo esteja sendo liquidado com osso e tudo. Pois mesmo na sua negação pura e simples, na supressão da mônada através da solidariedade, estaria plantada ao mesmo tempo a salvação do ser singular, que apenas na sua relação com o universal tornar-se-ia um particular. A situação atual está muito distante disso. Em meio às unidades humanas padronizadas e administradas, o indivíduo vai perdurando. Seu temperamento vivo e sem inibição, suas ideias inesperadas, sua originalidade, ainda que isso não passe de uma particular feiura, até mesmo sua algaravia, transforma o que é humano em traje de clown. Submetidos ao mecanismo universal da concorrência e não podendo se adequar ao mercado nem se impor nele de outra forma que não seja através da fixação de sua alteridade, mergulham de maneira apaixonada no seu próprio privilégio, exagerando a tal ponto que chegam a erradicar por completo aquilo que são tomados. Eles se vendem como fornecedores de calor humano em meio a frieza comercial [...]. (HORKHEIMER; ADORNO, 1985, p. 118). 
Os conteúdos sob a égide da cultura digital, por serem veiculados nos aligeiramentos e imediatismos informativos, sustentam um empobrecimento civilizatório que resulta numa formação regressiva dos indivíduos aos modelos do mercado e da sociedade instrumental e, por que não, de sua própria educação danificada.

A ilusão de liberdade do usuário ao retirar seu dispositivo móvel do bolso e acessar a internet nos mais variados formatos (fotos, vídeos, textos, músicas), em tempo real, não é atualmente um privilégio de determinada classe social. 0 crescimento de usuários é exponencial. Entretanto, a democratização não vem seguida de uma consciência para operar tais equipamentos. Por outro lado, como levar a cabo uma forma de não aderir ao famoso Gafam (Google, Apple, Facebook, Amazon e Microsoft), aos conglomerados financeiros que ditam o mundo? É possível que o cidadão comum não utilize tais serviços e dispositivos, abrindo mão da comodidade em nome da privacidade e da busca por uma subjetividade não forjada pelas redes?

As respostas a essas indagações requerem aportes de natureza política e sociológica, pois não se trata de uma escolha individual do cidadão, uma vez que os serviços estão à disposição com a falsa ideia de gratuidade, gerando formas incontáveis de comodidades e benefícios, sendo que os aspectos negativos, já tangenciados, não são visíveis tão facilmente. Essa limitação, no entanto, não é suficiente para reduzir a extensão do problema, pois é preciso desenhar novas ambiências entre os sistemas de informação e comunicação e a vida dos indivíduos. Importante ressaltar também que os governos de diversos países se aproveitam das fragilidades do cidadão em momentos oportunos (principalmente nas eleições), propalando "pós-verdades" em seu próprio benefício, contribuindo, assim, para uma sociedade programada, mecanizada a agir e pensar sob determinadas óticas.

Citamos como exemplo o ocorrido tanto nas eleições para presidente nos Estados Unidos da América quanto na eleição brasileira, no tocante à impulsionização de informações pagas ao Google e empresas contratadas para criação de fake news. No tocante aos conceitos, pode-se diferenciar fake news e pós-verdade. Enquanto o primeiro termo são notícias criadas com certas intenções, o segundo se refere a fatos alternativos acerca de determinado objetivo, fenômeno ou acontecimento. Tais expressões e fenômenos passaram a fazer parte de nosso cotidiano. 
Analisando o cenário atual, que é de certa forma caótico, levanta-se como hipótese que a realidade pode ser forjada e manipulada dependendo dos interesses de cada pessoa, grupos ou estado-nação. Elencando outro aspecto da mesma problemática, a forma como os algoritmos são organizados propicia ao sujeito a necessidade de conexão full time, de "ser e estar" na rede, de interagir, mostrar e demonstrar, de ver e ser visto. O efeito psicológico oriundo da organização dos dados nos instiga a ser e estar nesse espaço virtual, quase como uma necessidade indiscutivel.

Nesse sentido, ao analisar o mesmo episódio de "Queda Livre" em Black Mirror, comparando-o com a realidade, Lemos (2018) aponta que, quando agimos nessa rede, estamos em meio a essa expansiva monetização do capital social, fruto de uma vigilância distribuída e administrada por empresas privadas.

Colbo (2018), em entrevista na cidade de Lisboa, enfatiza de maneira mais trágica que é mais difícil sair da sobre-exposição digital do que da cocaína. Porque, quando se sai da cocaína, acaba-se, termina-se. Mas o digital é diferente, continua-se a conviver com ele. O nosso problema hoje é a conexão, e não o isolamento. É saber lidar com essa relação permanente com pessoas, objetos, dados e informações, e todas as formas de performances (LEMOS, 2018).

Sobre essa questão, Türcke (2010) denominou como "distração concentrada". Ao acessarmos as informações nos mais variados sites, a nossa capacidade de atenção é esfacelada assim que novos links, ou seja, novas ligações com outros sites têm êxito em conquistar nosso interesse, mesmo que por um instante, de tal forma que "o meio de concentração se torna o próprio meio de decomposição" (TÜRCKE, 2010, p. 266).

Ainda, é nessa sociedade que "[...] o grande recheio do tempo livre, penetrou profundamente, por meio do computador, o mundo do trabalho; a coordenação de processos inteiros de produção e administração perpassa por ela, de tal modo que se apresenta como o ensino do futuro" (TÜRCKE, 2010, p. 266-267). Nesse sentido, as barreiras são rompidas pelo consumo de estímulos audiovisuais, propagados pelas telas que tornam onipresentes todas as relações sociais dos indivíduos, sem falar da necessidade precisa de "resposta" do outro lado, em que reina a rapidez e impulsividade no trato dos assuntos diversos. Deixar o outro "esperar" torna-se um ato deselegante e, ainda, pode gerar prejuízos de ordem pessoal e profissional. Assim, essa complexidade gera a compreensão problemática da 
capacidade de o indivíduo se relacionar nesse contexto regido pelas redes sociais, mesmo considerando que, tecnicamente, a cultura digital esteja amparada pelo viés de vantagens associadas à velocidade e transitoriedade na esfera das redes.

\section{DA NECESSIDADE DE UMA CIDADANIA TECNOLÓGICA CRÍTICA: CONSIDERAÇÕES FINAIS}

Para concluir/finalizar, retomamos o objetivo deste ensaio, que é o de refletir em relação à constituição do sujeito no contexto das redes sociais e pensar a respeito desses impactos no processo de rompimento das fronteiras do indivíduo nessa terra comum. A partir disso, fazem-se necessárias e urgentes reflexões mais profundas acerca desse novo modo de ser e de estar dos sujeitos.

O advento da cultura digital e da ampliação das redes sociais de informação e comunicação não garantiu a emancipação e a conquista de suas necessidades humanas. Na verdade, o progresso técnico causou a regressão e irracionalidade, sendo, portanto, um paradoxo. Ao encontro dessas ideias, Adorno (1996, p. 401) menciona que "na verdade, o progresso evidente, a elevação geral do nível de vida com o desenvolvimento das forças produtivas, não se manifesta nas coisas espirituais com efeito benéfico".

As redes sociais, que têm como pano de fundo a cultura digital, imprimem a sensação de aparente liberdade política, econômica, cultural e moral que, de fato, não se concretiza. Diante disso, Castells (2013) afirma que é preciso pensar nas redes de indignação e esperança no sentido de tomada de consciência e resistência em sintonia com a formação emancipatória, como as tecnologias de transmissão de imagens na rede, que funcionam como forma de proteção contra a violência. Cabe aqui ressaltar que o mau uso das redes sociais provoca o aprisionamento intelectual, moral e físico e, por que não dizer, o perigoso deleite da neutralidade científica.

A esse respeito, Zuin (1999, p. 17) elucida:

É o homem que deve assumir o controle de suas próprias atividades, pois ele possui as capacidades cognitivas e afetivas necessárias para a realização dessa empreita. Se realmente o erro provém de fato de que nossa vontade é infinita e nosso entendimento é finito, e que, quando exercemos nosso livre arbítrio, em certas ocasiões, a vontade acaba por obscurecer a própria luz natural quando julgamos alguma coisa, por outro lado, é nos propiciada a oportunidade de controle de nossa vontade. 
Em sintonia com o desejo de uma nova cultura econômica e política, articulada por meio de redes de solidariedade, há possibilidade de se estabelecer um movimento de autorreflexão e crítica e, ainda, reflexão sobre o sistema de maneira contextualizada e emancipatória. Para tanto, torna-se fundamental que o indivíduo reavalie sua própria condição de sujeito social e pertencente nessa terra comum. Em relação a isso, Horkheimer (1991) assevera que o pensamento crítico é movido pelo anseio de uma efetiva aproximação entre os desejos individuais e coletivos, na busca de uma reconciliação verdadeira, e, ao mesmo tempo, pela necessária denúncia e crítica às falsas reconciliações impelidas pelas redes sociais.

Não podemos ignorar aspectos importantes positivos no tocante às redes. As pesquisas de recepção vêm sinalizando para modos de usos sociais das mídias que se estendem ou desdobram para além dos momentos e espaços de consumo midiático. Isso pode gerar dinâmicas comunicacionais que, embora guardem marcas, podem assumir certa autonomia ou constituir repertórios próprios em relação a essas materialidades (COGO; BRIGNOL, 2011).

Entretanto, a autonomia e a criação de repertórios só podem existir se imbuídas de uma formação consistente e crítica. Os indivíduos precisam desenvolver o exercício da experiência do pensar crítico, compreender toda a dinâmica das redes sociais e os impactos na subjetividade (ser e estar) humana no contexto da sociedade da cultura digital, para, assim, apropriar-se qualitativamente do que pode ser aproveitado em termos de rede de informação e comunicação.

Castells (2013) ressalta a importância da horizontalidade das redes sociais (questões locais e globais, o poder das imagens) e orienta-nos a pensar no projeto de antítese ao que tem se constituído enquanto dinâmica social da cultura digital. Dessa forma, abre-nos possibilidades para olhar além das telas da tecnologia da informação e comunicação, no sentido de pensarmos em novos direcionamentos de "ser e estar" no mundo, como possibilidade crítica de ora aceitar, ora não aceitar, resistir e, por que não, desbarbarizar.

Para Castells (2013), mesmo com todo o seu teor e viés econômico, criadas num momento em que a sociedade está altamente verticalizada, as relações sociais horizontalizadas podem ser a tentativa de desbarbarizar. Sobre essa discussão, o autor afirma:

A elasticidade da Internet a torna particularmente suscetível a intensificar tendências contraditórias presentes em nosso mundo. Nem utopia nem 
distopia, a Internet é a expressão de nós mesmos através de um código de comunicação específico, que devemos compreender se quisermos mudar nossa realidade. [...] [A invenção da Internet] reforça também a ideia de que a cooperação e a liberdade de informação podem ser mais propícias à inovação do que a competição e os direitos de propriedade. (CASTELLS, 2003, p. 75).

Nesse prisma, a formação crítica e emancipatória do indivíduo diante do que tem se instituído deve avançar na direção contrária, mas em direção de uma reflexão crítica e comprometida com a história social dos homens. A função primordial é de resistência ao inumano e, à medida que a consciência crítica permite a percepção da inumanidade do próprio homem, da barbárie, instaurada na história pelos sofrimentos e traumas provocados pelo desenvolvimento tecnológico, podemos pensar na capacidade de refletir para inventar e, quem sabe, começar de novo.

\section{REFERÊNCIAS}

ADORNO, T. W.; HORKHEIMER, M. Dialética do esclarecimento. Rio de Janeiro: Zahar, 1985.

ADORNO, T. W. Teoria da Semicultura. Tradução de Newton Ramos-de-Oliveira, Bruno Pucci, Cláudia B. Moura Abreu (coop. Paula Ramos-de-Oliveira). Educação e Sociedade: Revista Quadrimestral de Ciência da Educação. Campinas, Ano XVII, n. 56, dez. 1996.

BATELLE, J. A busca: como o Google e seus competidores reinventaram os negócios e estão transformando as nossas vidas. São Paulo: Elsevier/Campus, 2006.

CASTELLS, Manoel. A Galáxia da internet: reflexões sobre a internet, os negócios e a sociedade. Rio de Janeiro: Zahar, 2003.

CASTELLS, Manuel. Redes de indignação e esperança: movimentos sociais na era da internet. Tradução de Carlos Alberto Medeiros. Rio de Janeiro: Zahar, 2013. 271 p.

COGO, Denise; BRIGNOL, Liliane D. Redes sociais e os estudos de recepção na internet. Matrizes, Ano 4, n. 2, jan/jun. 2011. Disponível em: https://www.revistas.usp.br/matrizes/ article/view/38293/41117. Acesso em: 15 abr. 2019.

COLBO, C. Acepto las Condiciones: usos y abusos de las tecnologías digitales. Madrid: Fundación Santillana, 2019. 
COLBO, C. As pessoas são mais do que um conjunto de dados. Entrevista concedida a Rita Pimenta. Público, 5 nov., 2018. Disponível em: https://www.publico.pt/2018/11/05/ sociedade/entrevista/cristobal-cobo-pessoas-sao-conjunto-dados-1849866. Acesso em: 15 abr. 2019.

DANTAS, M. Internet e geração de valor no capitalismo espetacular. In: TAVARES, R. H.; GOMES, S. S. (Org). Sociedade, educação e redes: desafios à formação crítica. Araraquara, SP: Junqueira \& Martins, 2014. p. 79-124.

DELEUZE, G. Conversações: 1972-1990. São Paulo: Editora 34, 1992. p. 219-26.

HORKHEIMER, M. Teoria tradicional e teoria crítica. Tradução de Edgard Afonso Malagodi e Ronaldo Pereira Cunha. In: HORKHEIMER, M.; ADORNO, T. W. Coleção "Os Pensadores". São Paulo: Nova Cultural, 1991.

LEMOS, André. Isso (não) é muito Black Mirror: passado, presente e futuro das tecnologias de comunicação e informação. Salvador: EDUFBA, 2018.

PORTUGAL, Silvia. Contributos para uma discussão do conceito de rede na teoria sociológica. Oficina do CES, n. 271, mar. 2007.

TAVARES, R. H.; GOMES, S. S. (Org.). Sociedade, educação e redes: desafios à formação crítica. Araraquara, SP: Junqueira \& Martins, 2014, p. 79-124.

TÜRCKE, C. Sociedade excitada: filosofia da sensação. Campinas, SP: Editora da Unicamp, 2010.

TÜRCKE, Christoph. Sociedade da sensação: a estetização da luta pela existência. In: ZUIN, Antônio; PUCCI, Bruno; RAMOS-DE-OLIVEIRA, Newton (Org.). Ensaios Frankfurtianos. São Paulo: Cortês, 2004. p. 31-73.

ZUIN, A. A. S. Indústria cultural e educação: o novo canto da sereia. Campinas, SP: Autores Associados, 1999.

ZUIN, A. S. A cultura digital, a semiformação e o novo elo pedagógico. Inter-Ação, Goiânia, v. 39, n. 2, p. 241-256, maio/ago. 2014.

\section{Sobre as autoras:}

Diene Eire de Mello: Pós-doutorado pela Universidade Aberta de Portugal (UAb). Doutorado em Educação pela Universidade Estadual de Maringá (UEM). Mestrado 
em Tecnologias com Ênfase em Educação pela Universidade Tecnológica Federal do Paraná (UTFPR). Pedagoga. Docente do Departamento de Educação do Programa de Pós-Graduação da Universidade Estadual de Londrina (UEL). E-mail: diene.eire.mello@gmail.com, Orcid: http://orcid.org/0000-0001-6048-8130

Marta Furlan de Oliveira: Pós-doutorado em Educação pela Universidade Estadual Paulista Júlio de Mesquita Filho (Unesp). Doutorado e mestrado em Educação pela Universidade Estadual de Maringá (UEM). Graduação em Pedagogia pela Universidade Estadual de Londrina (UEL). Docente do Programa de Pós-Graduação em Educação da UEL. E-mail: marta.furlan@yahoo.com.br, Orcid: http://orcid.org/0000-0003-2146-2557

Recebido em: 10 de maio de 2019

Última revisão: 15 de maio de 2020

Aprovado em: 28 de julho de 2020 